\title{
Analysis on Energy Saving of Intermittent Operation Control of University Building Heating System
}

\author{
Xiang Pei \\ Shandong Huayu Unversity of Technology, Dezhou, Shandong Province,
}

\begin{abstract}
With the continuous expansion of college campuses, the heating area is increasing, and the demand for heating is also increasing. The heating system needs to face multiple pressures on the environment, resources, safety, and economy. Operation and regulation are the key points of energy saving and emission reduction in college heating in the future. This article analyzes the intermittent operation of the university building system, mainly from the analysis of the heating pipe network zoning setting, the establishment of the heating intermittent operation control mechanism, and the optimization of the intermittent operation adjustment scheme. From the analysis of simulation results of intermittent operation adjustment and optimization schemes, comparison with actual heating energy consumption analysis and energy saving analysis of optimization schemes, it is proposed that intermittent operation control of heating systems has great potential for energy saving.
\end{abstract}

\section{Zoning setting of college heating network}

Taking a university in Dezhou, Shandong Province as an example, the university buildings are mainly divided into the following categories: student dormitory buildings, classroom office buildings, student teaching buildings, libraries, teacher apartments, restaurants, etc. Due to different building functions, the interior of the building is heated The required time is also different. According to the function of the building, the heating time of the building is divided, and the heating zoning of the building is reasonably divided according to the heating needs of different buildings.

The student dormitory is full-day and needs all-day heating and is a partition; the teaching building is used by students for class, almost concentrated before 10:30 during the day and at night, and is a partition; the teacher 's office building is the main place for teachers 'working hours According to the difference between teachers 'commuting time and students' work and rest, it is regarded as a partition; the teacher's apartment is a place for teachers to rest, and is divided into a partition according to the teacher's rest and work. The restaurant mainly gathers a large number of people for three meals a day. The indoor work and rest time is unique, and it is set as a separate zone.

\section{Establishment of intermittent operation control mechanism}

The intermittent operation of the building heating system can make good use of the heat storage performance of the building, reasonably realize the energy saving of the building heating operation under the condition of ensuring the indoor heating temperature of the building. According to the analysis of the simulation results of the intermittent operation time of different building heating, it can be obtained that the intermittent heating of the building It can save the building energy consumption while ensuring that the interior reaches the design temperature. According to the simulation results of the intermittent operation time of heating in different buildings as a reference, the control mechanism of intermittent operation at different times is established as follows:

Table 1. Control mechanism of intermittent operation of buildings.

\begin{tabular}{cccc}
\hline $\begin{array}{c}\text { paramet } \\
\text { er }\end{array}$ & Option 1 & Option 2 & Option 3 \\
\hline Intermitt & $11: 00-13: 00$ & $15: 00-17: 00$ & $11: 00-13: 00$, \\
ent & intermittent & intermittent & $15: 00-17: 00$ \\
heating & Stop heating & Stop heating & intermittent \\
time & & & Stop heating \\
setting & & & \\
\hline
\end{tabular}

The above table shows three schemes for the intermittent heating operation control mechanism of the building. Since the option 1 and 2 can meet the indoor heating demand, according to the combination of option 1 and soption 2 , the option 3 is the intermittent heating

\footnotetext{
*Corresponding author: sddzxp@163.com
} 
control mechanism optimization plan.Option 1 uses 11 o'clock and 12 o'clock when the solar radiation is strong at noon to turn off the indoor heating. Since some of the residual heat in the indoor heating equipment can be radiated to the room after the indoor heating is turned off, it is more reasonable to shut down the indoor heating during this time period, This scheme as one of the schemes of heating intermittent operation control mechanism.

Option 2 adopts 15: 00 and 16: 00 when the building envelope structure such as wall in the afternoon absorbs solar radiation and stores more heat to shut down the indoor heating. Firstly, after the indoor heating is closed, some residual heat in the indoor heating equipment can still be radiated to the room; Secondly, the building envelope structure has more heat storage at this time, the temperature is relatively high, and the heat dissipation from the indoor to the outdoor is small. Therefore, it is reasonable to turn off indoor heating during this time period, and also use this scheme as a control mechanism for intermittent heating operation. One of the programs.

Option 3 uses 11 o'clock and 12 o'clock when the solar radiation is strong to close the indoor heating, and at 15 o'clock and 16 o'clock when the building envelope such as the wall absorbs solar radiation and stores more heat. Due to the strong solar radiation at 11 and 12 noon, there will be more heat entering the room through the transparent enclosure; secondly, there is still some residual heat in the indoor heating equipment that can be dissipated into the room; finally, the building enclosure at 15 and $16 \mathrm{pm}$ At this time, the structure has more heat storage, the temperature is relatively high, and the heat dissipation from the indoor to the outdoor is small. Therefore, it is more reasonable to turn off indoor heating during these two periods.

\section{Optimization of intermittent operation regulation scheme}

According to the research on the intermittent operation time of different building heating, the Energyplus energy consumption simulation software is used to establish the energy consumption model, and the indoor temperature and heating energy consumption of the intermittent heating operation time optimization scheme are simulated, and the energy saving of the optimization scheme is obtained through simulation. An optimized plan for intermittent heating operation regulation is provided to provide a basis for heating and energy saving in college buildings.

\subsection{Simulation setting of intermittent operation adjustment optimization scheme}

The settings in the simulation mainly include the operating time of the system throughout the year and daily, the interior design temperature, the number of indoor personnel and the heat dissipation internal power density of the lighting equipment, the thermal parameters of the enclosure structure, outdoor weather conditions, etc. The specific settings are as follows:
Table 2. Simulation parameter settings.

\begin{tabular}{|c|c|}
\hline Parameter & Simulation settings \\
\hline $\begin{array}{l}\text { Annual } \\
\text { Operating Time } \\
\text { of system }\end{array}$ & $\begin{array}{l}\text { Normal heating from January } 1 \text { st to } \\
\text { January20th, March } 4 \text { th to March } 15 \text { th } \\
\text { and November } 15 \text { th to December } 31 \text { st; } \\
\text { January } 21 \mathrm{st} \text { to March } 3 \text { th guarantee } \\
\text { indoor } 5{ }^{\circ} \mathrm{C} \text { antifreeze heating }\end{array}$ \\
\hline $\begin{array}{l}\text { Daily operating } \\
\text { time of the } \\
\text { system }\end{array}$ & $\begin{array}{l}\text { 11:00-13:00, } 15: 00-17: 00 \text { stop heating } \\
\text { intermittently }\end{array}$ \\
\hline $\begin{array}{l}\text { Interior design } \\
\text { temperature }\end{array}$ & $\begin{array}{c}\text { 0:00-7:00 Interior design temperature } \\
5^{\circ} \mathrm{C}, 7: 00-22: 30 \text { Interior design } \\
\text { temperature } 18^{\circ} \mathrm{C}, 22: 30-24: 00 \text { Interior } \\
\text { design temperature } 5^{\circ} \mathrm{C}\end{array}$ \\
\hline $\begin{array}{l}\text { Number of } \\
\text { indoor staff }\end{array}$ & $\begin{array}{l}\text { Calculated according to the personnel } \\
\text { density of } 0.3 \text { people } / \mathrm{m}^{2}\end{array}$ \\
\hline $\begin{array}{l}\text { Indoor lighting } \\
\text { power density }\end{array}$ & Calculated by $10 \mathrm{~W} / \mathrm{m}^{2}$ \\
\hline $\begin{array}{l}\text { Indoor } \\
\text { equipment power } \\
\text { density }\end{array}$ & Calculated by $5 \mathrm{~W} / \mathrm{m}^{2}$ \\
\hline $\begin{array}{l}\text { Outdoor weather } \\
\text { conditions }\end{array}$ & $\begin{array}{l}\text { Adopt } 8760 \text { hours of hourly } \\
\text { meteorological data in the typical } \\
\text { meteorological year of Dezhou }\end{array}$ \\
\hline
\end{tabular}

\subsection{Simulation results of intermittent operation adjustment optimization scheme}

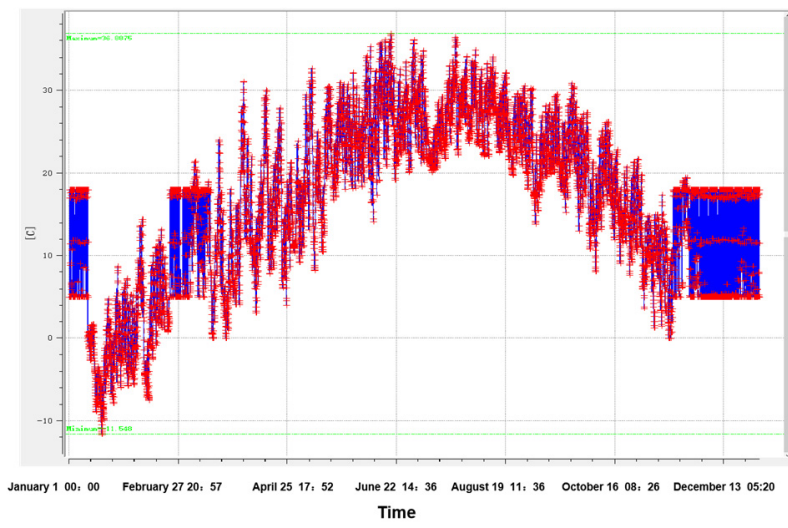

Fig.1. The simulation diagram of the indoor hourly temperature simulation scheme.

The picture above shows the simulation results of the indoor hourly temperature in the heating season of the optimization scheme. From the above picture, except for the winter vacation from January 20 to March 4, the indoor temperature in the daytime is maintained at $18{ }^{\circ} \mathrm{C}$, and the night temperature is maintained at $5{ }^{\circ} \mathrm{C}$, the indoor temperature meets the design requirements. During the winter holidays, due to the cold weather, there is no personnel activity in the room. In order to prevent freezing, the indoor temperature is maintained at $5{ }^{\circ} \mathrm{C}$ throughout the day, and the low temperature operation mode is adopted. 
Hourly air conditioning load throughout the year

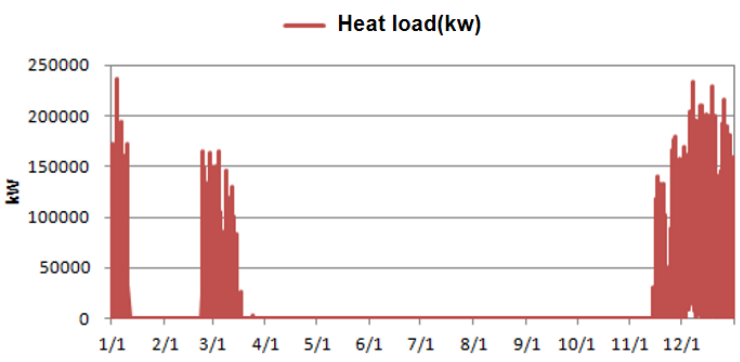

Fig. 2. Simulation diagram of indoor hourly energy consumption of the timization scheme.

The picture above shows the simulation results of the hourly energy consumption of indoor heating in the heating season of the optimization scheme. It can be obtained from the picture above. Except for the winter vacation from January 20 to March 4, the building needs building heating throughout the day, and there is heating energy consumption, Where the temperature is set to $18{ }^{\circ} \mathrm{C}$ indoors during personnel activities, the building heating energy consumption is significantly larger, the use of low temperature heating at night to prevent indoor freezing when the building heating energy consumption is small, the outdoor temperature at night is lower than the outdoor temperature during the day, but due to the indoor The lower temperature setting is $5^{\circ} \mathrm{C}$, so the energy consumption of the building at night is low within a reasonable range.

Table 3. cumulative building energy consumption of intermittent operation control scheme for heating

\begin{tabular}{lccc}
\hline $\begin{array}{l}\text { Parameter } \\
\text { Cumulative } \\
\text { energy } \\
\text { consumption for } \\
\text { heating (kw) }\end{array}$ & Option 1 & Option 2 & Option 3 \\
\hline
\end{tabular}

From the above table, it can be concluded that the optimization scheme 3 has greater energy saving potential than scheme 1 and scheme 2.Based on the above analysis, it can be concluded that the intermittent operation of building heating can reduce indoor heating energy consumption while ensuring the building heating temperature, and the use of different intermittent control mechanisms can maximize energy consumption savings under the premise of satisfying indoor comfort.

\section{Analysis of actual heating energy consumption}

The actual heating of the university adopts the continuous heating mode. The design value of the indoor heating temperature is $18^{\circ} \mathrm{C}$ from $7: 00$ am to $22: 30$ in the evening, and the indoor heating temperature is $5^{\circ} \mathrm{C}$ from 22:30 pm to 7:00 the next morning. When intermittent heating measures are not taken, the actual heating energy consumption test results are analyzed as follows.

\subsection{Analysis of actual heating energy consumption}

According to the heating energy consumption test results of the university, the indoor temperature and heating energy consumption of the teaching building of the university were selected on December 29, and at the same time, the heating temperature and energy consumption of the best intermittent optimization scheme Scheme 3 simulated by the energy consumption model Compare and analyze the energy saving and environmental benefits of the optimized plan.

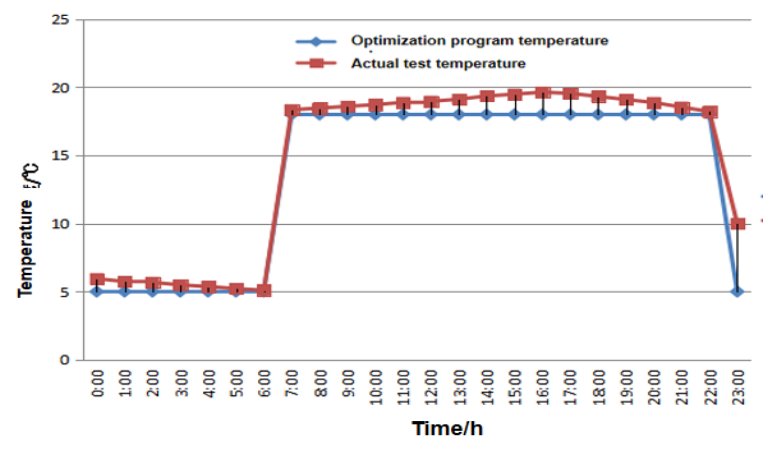

Fig. 3. 12-29 actual test room temperature value 24 hours.

The picture above shows the actual test heating room temperature and the simulated emperature value of the optimization plan. During the heating period, the actual test temperature in the room will be higher than the indoor design temperature from 7:00 am to $22: 30 \mathrm{pm}$ on December 29 . The hourly temperature is $18^{\circ} \mathrm{C}$, which is the same as the interior design temperature. The reason why the actual test temperature in the room is higher than the design temperature is that there are more students in the classroom on that day, the attendance rate in the classroom is larger, the indoor heat source is larger, and the indoor heat dissipation is larger, so this is an advantageous factor in the heating season. The temperature is $18^{\circ} \mathrm{C}$ higher.

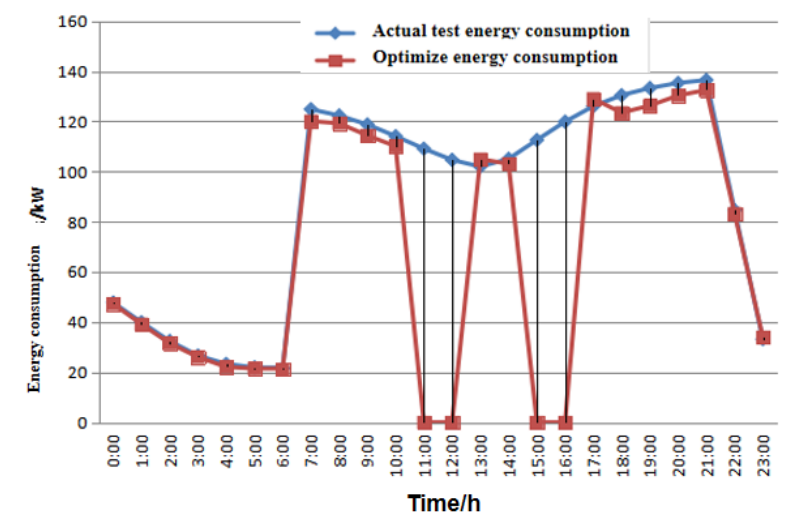

Fig.4. 12-29-24-hour actual test heating energy consumption of teaching buildings.

The picture above shows the comparison between the actual energy consumption of the teaching building on December 29 and the simulated energy consumption value of the optimization plan. From the picture above, it can be seen that the energy consumption of building heating during the intermittent period is 0 , and within one 
hour of heating just after the interval, The building heating energy consumption has a sudden increase trend, and then gradually decreases, because within two hours when the building stops heating, the building envelope radiates heat to the indoor and outdoor, the temperature decreases, the heat storage becomes smaller, when the building begins to heat, the building The envelope structure absorbs more heat, so the energy consumption of heating required at this time is larger, and there is a sudden increase compared to continuous heating.

Through analysis, the actual heating energy consumption for the entire heating season is $742643.6 \mathrm{kWh}$, and the optimal solution for intermittent heating is $680552 \mathrm{kWh}$ for the entire heating season, which is $62091.6 \mathrm{kWh}$ of electricity compared to the continuous heating mode.

\subsection{Analysis of energy saving of optimization plan}

According to the above analysis of the optimization plan and actual test results, the heating season is more energy-saving when using the intermittent operation plan. The energy savings of the intermittent operation optimization plan and the actual operation test are as follows:

Annual heating energy consumption area index:

$$
q=Q / F
$$

In the formula,

$\mathrm{q}$-Annual heating energy consumption area index, $\mathrm{kwh} /\left(\mathrm{m}^{2} \cdot \mathrm{a}\right)$

$\mathrm{Q}$-Annual cumulative heating energy consumption

$\mathrm{F}$-Heating area

According to the above formula, the actual annual heating energy consumption area index:

$$
q_{S}=Q_{1} / F=742643.6 / 17540=42.34 \mathrm{kWh} /\left(\mathrm{m}^{2} \bullet a\right)
$$

Intermittent operation optimization scheme Annual heating energy consumption area index:

$$
q_{m}=Q_{2} / F=680552 / 17540=38.8 \mathrm{kWh} /\left(\mathrm{m}^{2} \bullet a\right)
$$

The annual energy consumption per unit area of heating energy consumption is $3.54 \mathrm{kWh} /\left(\mathrm{m}^{2} \cdot \mathrm{a}\right)$.

Based on the conversion of standard coal coefficient of $0.1229 \mathrm{kgce} / \mathrm{kWh}$, the actual heating system consumes $742643.6 \times 0.1229=91270.9 \mathrm{kgce}$, and the annual standard coal consumption per unit area is $5.2 \mathrm{kgce} /\left(\mathrm{m}^{2} \cdot \mathrm{a}\right)$; the intermittent operation optimization program annual heating consumption Standard coal $680552 \times 0.1229=83639.8 \mathrm{kgce}$, the annual standard coal consumption per unit area is $4.77 \mathrm{kgce} /\left(\mathrm{m}^{2} \cdot \mathrm{a}\right)$; the optimization scheme saves $7542.2 \mathrm{kgce}$ standard coal compared with the actual operating year; the annual standard coal savings per unit area is $0.43 \mathrm{kgce} /\left(\mathrm{m}^{2} \cdot \mathrm{a}\right)$.

\section{Summary}

Through the optimization of the control mechanism under the intermittent operation of building heating, it is concluded that the intermittent heating operation plan that stops heating from 11:00 to 13:00 in the morning and 15:00 to 17:00 in the afternoon can ensure the indoor heating effect and consume energy The lowest, which has greater advantages compared to the other two intermittent operation schemes, and provides a reference for the optimization design of intermittent heating. At the same time, through the comparison of the optimal intermittent optimization scheme energy consumption simulation data and the actual test energy consumption simulation data, it is found that the intermittent operation optimization scheme Compared with the actual heating operation, the energy saving is $62091.6 \mathrm{kWh}$, and the annual energy consumption per unit area of heating energy consumption is $3.54 \mathrm{kWh} /\left(\mathrm{m}^{2} \cdot \mathrm{a}\right)$; the conversion of standard coal saves $7542.2 \mathrm{kgce}$, and the annual standard coal saving per unit area is $0.43 \mathrm{kgce} /\left(\mathrm{m}^{2} \cdot \mathrm{a}\right)$. It has laid a theoretical foundation for the optimal operation of intermittent heating in subsequent college buildings.

\section{References}

1. Teng Shixing, Shao Zongyi. Study on optimal configuration of heating system — Taking the new campus of Beijing Institute of Architecture and Engineering as an example J. Journal of Beijing Institute of Civil Engineering, 2010, 26(4): 20-24.

2. Cao $\mathrm{Fu}, \mathrm{A}$ study on the regulation and control of time-division and district heating quality of secondary network system. Southwest Jiaotong University, 2014.

3. Zheng Xiangyu, Lu Dongpei, Wang Xin. Application of time-sharing and zone-division automatic control in energy-saving of heating pipe network J. Gas and heat, 2015, 35(3):14-18.

4. Abdurafikov R, Grahn E, Kannari L, et al. An analysis of heating energy scenarios of a Finnish case district[J]. Sustainable Cities and Society, 2017, 32: 56-66.

5. Sun Qingdian, an Lin, Liu Yufeng. Research and application of heating energy-saving control system for campus buildings J. Building energy efficiency, 2009, 37(6): 27-29. 